\title{
Studies on the Reduction of $\beta$-Enamino Ketones
}

\author{
Melina A. Machado, Maria Inês N. C. Harris and Antonio C. H. Braga* \\ Instituto de Química, Universidade Estadual de Campinas CP 6154, 13084-971 Campinas-SP, Brazil
}

\begin{abstract}
A redução de $\beta$-enamino cetonas 1 com $\mathrm{NaBH}(\mathrm{OAc})_{3}$ em ácido acético glacial produziu $\beta$ amino cetonas 3 em $65 \%$ a $67 \%$ de rendimento. Esses resultados, juntamente com outros, obtidos nas reduções de $\beta$-enamino cetonas $\mathbf{1}$ a $\gamma$-amino álcoois $\mathbf{2}$, preferencialmente syn, com $\mathrm{NaBH}_{4} / \mathrm{HOAc}$, sugerem que o curso reacional desta última reação passa inicialmente pela redução de $\beta$-enamino cetonas $\mathbf{1}$ a $\beta$-amino cetonas $\mathbf{3}$ e estas são reduzidas posteriormente a $\gamma$-amino álcoois 2. Com esses resultados podemos dizer que a diastereosseletividade da redução de $\beta$ enamino cetonas $\mathbf{1}$, a $\boldsymbol{\gamma}$-amino álcoois $\mathbf{2}$ dando preferencialmente produtos syn pode ser analisada como o resultado de uma competição entre um estado de transição tipo bote e um estado de transição tipo cadeira, obtidos a partir das $\beta$-amino cetonas $\mathbf{3}$.
\end{abstract}

Reduction of $\beta$-enamino ketones 1 with $\mathrm{NaBH}(\mathrm{OAc})_{3}$ in glacial acetic acid gave $\beta$-amino ketones 3 in $65 \%$ to $67 \%$ yield. These data and others observed in the reduction of $\beta$-enamino ketones 1 to preferentially syn $\gamma$-amino alcohols 2 with $\mathrm{NaBH}_{4} / \mathrm{HOAc}$ suggest that in this last reaction we have firstly the reduction of the $\beta$-enamino ketones $\mathbf{1}$ to produce the $\beta$-amino ketones $\mathbf{3}$, and then this compound is reduced to the $\gamma$-amino alcohols $\mathbf{2}$. We can say from this results that the diastereosselectivity of the reduction of $\beta$-enamino ketones $\mathbf{1}$ to mainly syn $\gamma$ amino álcohols $\mathbf{2}$, can be analysed as a competition between a chair-like transition state and a boat-like transition state, obtained from the $\beta$-amino ketones $\mathbf{3}$.

Keywords: amino alcohols, enamino ketones, amino ketones, Mannich base

\section{Introduction}

Recently, we reported an easy and efficient method to produce $\gamma$-amino alcohols 2 by reduction of $\beta$ enamino ketones 1 with $\mathrm{NaBH}_{4}$ in glacial acetic acid, which has been sucessfully used in our laboratory. ${ }^{1}$ Our results showed that the reaction of $\beta$-enamino ketones 1 with $\mathrm{NaBH}_{4}$ in glacial acetic acid (3 hours at room temperature) produces a mixture of syn/anti $\gamma$-amino alcohols 2 in $70 \%$ to $98 \%$ yield with diastereomeric excesses preferentially for the syn product, from $44 \%$ to $90 \%$. The use of $\mathrm{NaBH}_{4}$ in a carboxylic acid medium is well known, ${ }^{2}$ but its use in the reduction of $\beta$-enamino ketones 1 has not been explored. To continue our studies on the reduction of $\beta$-enamino ketones $\mathbf{1}$, and to understand the diastereoselectivity observed in the reduction to $\gamma$-amino alcohols 2 and the real reducing agent, we wish to report herein our results obtained with the reduction of $\beta$-enamino ketones $\mathbf{1}$ using $\mathrm{NaBH}(\mathrm{OAc})_{3} / \mathrm{HOAc}$.

*e-mail: herrera@iqm.unicamp.br

\section{Results and Discussion}

The reaction of $\mathrm{NaBH}_{4}$ with neat carboxylic acids leads to the formation of acyloxyborohydrides. ${ }^{2}$ Reaction with glacial acetic acid leads to the formation of acetoxyborohydrides of different hydride-donating abilities. Presumably the reactivity order $\left(-\mathrm{BH}_{3} \mathrm{OAc}>-\mathrm{BH}_{2}(\mathrm{OAc})_{2}\right.$ $\left.>-\mathrm{BH}(\mathrm{OAc})_{3}\right)$ is a consequence of both the inductive electron-withdrawing ability of the acetoxy group and the steric bulk surrounding the B-H bond. ${ }^{3}$ Although the reaction of $\beta$-enamino ketones 1 with $\mathrm{NaBH}_{4}$ in glacial acetic acid for 3 hours at room temperature leads to products from total reduction ( $\gamma$-amino alcohols $\mathbf{2}),{ }^{1}$ under the same conditions, using $\mathrm{NaBH}(\mathrm{OAc})_{3}$ as a reducing agent we have the Mannich base $\mathbf{3}$ as a product (Scheme 1, Table 1). These results are obtained when we add comercial $\mathrm{NaBH}(\mathrm{OAc})_{3}$ to a solution of $\beta$-enamino ketone $\mathbf{1}$ in glacial acetic acid or when firstly we add $\mathrm{NaBH}_{4}$ to glacial acetic acid and then add the $\beta$-enamino ketones $\mathbf{1}, 4,5$ and shows that in the reduction of the $\beta$-enamino ketones $\mathbf{1}$ to $\gamma$-amino alcohols 2, the reducing agent is not the $\mathrm{NaBH}(\mathrm{OAc})_{3}$ as it is normally interpreted in this type of reaction. ${ }^{7}$ These data 
imply that sodium borohydride added directly to acetic acid, as it is used in the total reduction of $\beta$-enamino ketones $\mathbf{1}$ to $\gamma$-amino alcohols $\mathbf{2}$, does not quantitatively give sodium triacetoxyborohydride. ${ }^{6}$

Table 1. Products obtained by reduction of $\beta$-enamino ketones $\mathbf{1}$ with $\mathrm{NaBH}(\mathrm{OAc})_{3} / \mathrm{HOAc}$

\begin{tabular}{llllc}
\hline 1 & $\mathrm{R}^{1}$ & $\mathrm{R}^{2}$ & $\mathrm{R}^{3}$ & $\% 3^{\mathrm{c}}$ \\
\hline $\mathbf{a}$ & $\mathrm{Me}$ & $\mathrm{Ph}$ & $\mathrm{H}$ & 67 \\
$\mathbf{b}$ & $\mathrm{Me}$ & $\mathrm{Bn}$ & $\mathrm{H}$ & 65 \\
$\mathbf{c}$ & $\mathrm{Me}$ & $\mathrm{ir}$ & $\mathrm{H}$ & 67 \\
$\mathbf{d}$ & $\mathrm{Ph}$ & $\mathrm{ir}$ & $\mathrm{H}$ & $\mathrm{a}$ \\
$\mathbf{e}$ & $\mathrm{Me}$ & \multicolumn{2}{c}{$-\left(\mathrm{CH}_{2}\right)^{-}$} & $\mathrm{H}$ \\
$\mathbf{f}$ & $\mathrm{Bu}$ & $\mathrm{Bn}$ & $\mathrm{H}$ & $\mathrm{b}$ \\
g & $\mathrm{Ph}$ & $\mathrm{Bn}$ & $\mathrm{H}$ & $\mathrm{a}$ \\
\hline
\end{tabular}

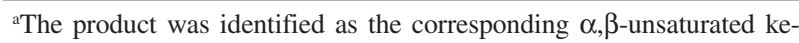
tone; bdecomposition during treatement; cisolated yield.

Early information showed that, when the reduction reaction of $\beta$-enamino ketones $\mathbf{1}$ to $\gamma$-amino alcohols $\mathbf{2}$ with $\mathrm{NaBH}_{4} / \mathrm{HOAc}$ is carried out without temperature control, the reaction produces the corresponding $\alpha, \beta$-unsaturated ketone, while at $0{ }^{\circ} \mathrm{C}$ (using hexane/HOAc, $\mathrm{CH}_{2} \mathrm{Cl}_{2} / \mathrm{HOAc}$ or HOAc as solvent) the product is a mixture of reactant $\mathbf{1}$, $\gamma$-amino alcohol 2 and the corresponding Mannich base $\mathbf{3}{ }^{1}$ This information suggests that the Mannich base $\mathbf{3}$ acts as an intermediate in this reaction. The parcial reduction of $\beta$-enamino ketones $\mathbf{1}$ to $\beta$-amino ketones $\mathbf{3}$ with $\mathrm{NaBH}(\mathrm{OAc})_{3} / \mathrm{HOAc}$ and the observation in some cases the corresponding $\alpha, \beta$-unsaturated ketones reinforces this suspicion. The $\beta$-amino ketones $\mathbf{3}$ obtained are very unstable and decompose rapidly to the corresponding $\alpha, \beta$-unsaturated ketones. They were immediately analysed on a Shimadzu GC/MS Class 500 chromatograph equipped with a Simplicity-1 (SUPELCO) column. All the chromatograms presented only one compound with the MS showing a typical fragmentation, as seen in Figure 1 and Table 2.

Another important observation is that it is not possible to reduce 3-(N-benzylamino)-2-cyclohexen-1-one using either $\mathrm{NaBH}_{4} / \mathrm{HOAc}$ or $\mathrm{NaBH}(\mathrm{OAc})_{3} / \mathrm{HOAc}$.

In conclusion, these observations suggest that in the reduction of $\beta$-enamino ketones $\mathbf{1}$ to $\gamma$-amino alcohol $\mathbf{2}$ we have firstly the reduction of the $\beta$-enamino ketones $\mathbf{1}$ to $\beta$-amino ketones $\mathbf{3}$, then this compound is further reduced to

Table 2. Typical fragmentation observed in the $\beta$-amino ketones $\mathbf{3}$

\begin{tabular}{lcc}
\hline $\mathbf{3}$ & $\mathbf{5}(\mathrm{m} / \mathrm{z})$ & $\mathbf{6}(\mathrm{m} / \mathrm{z})$ \\
\hline $\mathbf{a}$ & $43(67 \%)$ & $120(100 \%)$ \\
$\mathbf{b}$ & $43(57 \%)$ & $134(9 \%)$ \\
$\mathbf{c}$ & $43(67 \%)$ & $86(16 \%)$ \\
$\mathbf{e}$ & $43(74 \%)$ & $98(100 \%)$ \\
\hline
\end{tabular}

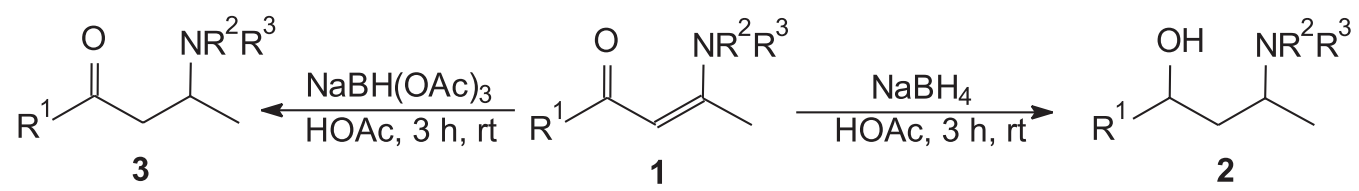

Scheme 1.

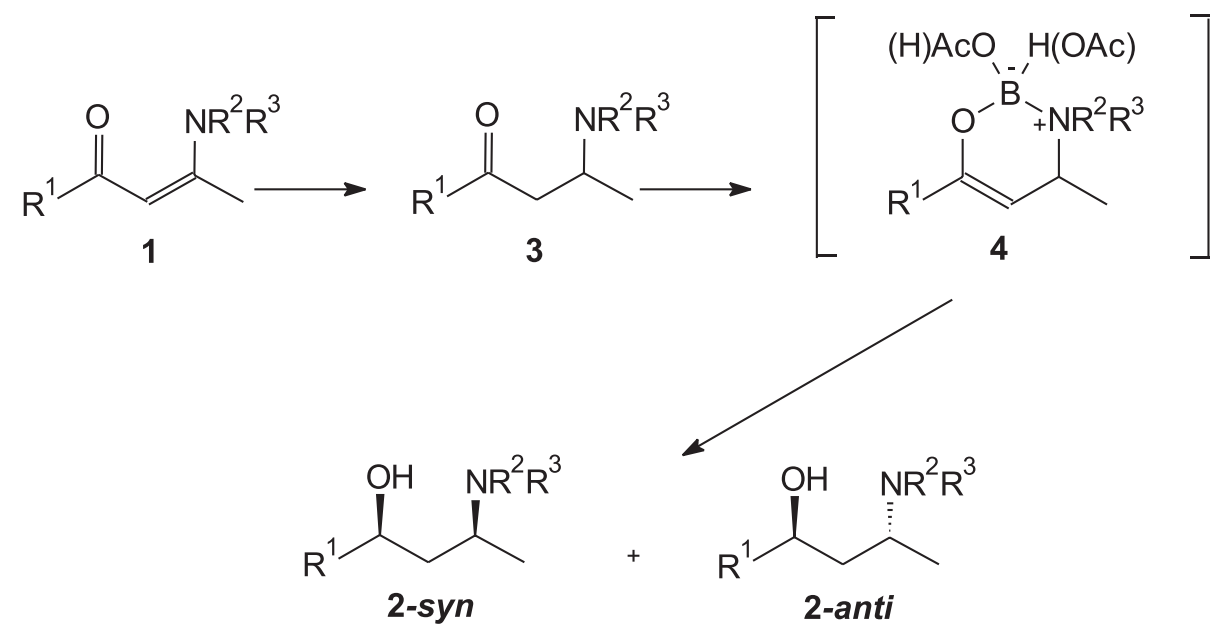

Scheme 2 . 


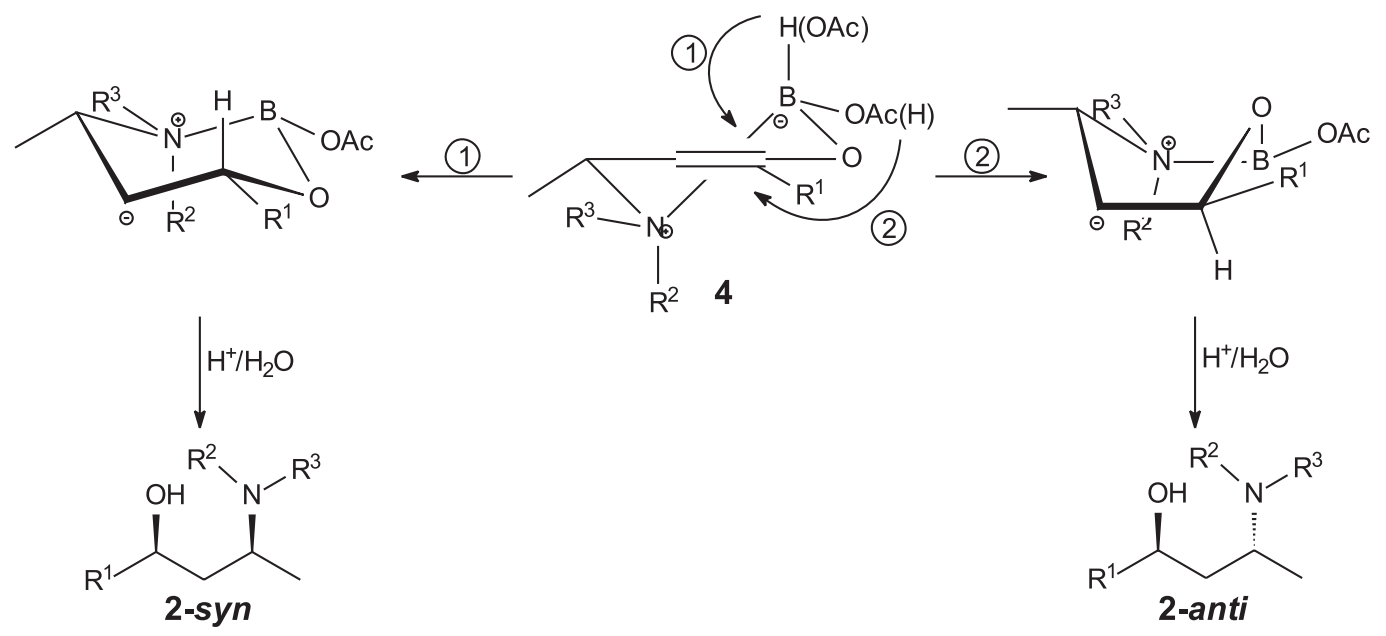

Scheme 3.

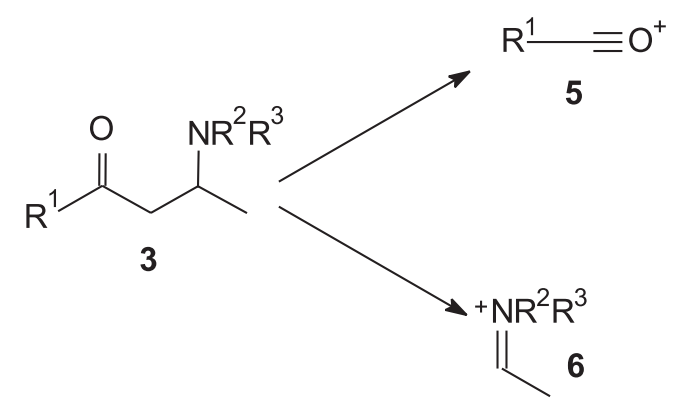

Figure 1. Typical fragmentation observed with the $\beta$-amino ketones 3 .

the $\gamma$-amino alcohols 2 (Scheme 2). The stereochemical course of these reductions, producing preferentially the syn$\gamma$-amino alcohols $\mathbf{2}$, may be rationalised via the different energies of the diastereomeric transition states resulting in a competition between a chair-like transition state and a boatlike transition state (Scheme 3), when the syn product is obtained by the lower energy route.

\section{Experimental}

General procedure to obtain $\beta$-amino ketones (3)

To a solution of $\beta$-enamino ketone $(\mathbf{1}, 1 \mathrm{mmol})$ in glacial acetic acid $(6 \mathrm{~mL})$, was slowly added $\mathrm{NaBH}(\mathrm{OAc})_{3}(4 \mathrm{mmol})$. The reaction was kept at $18-20{ }^{\circ} \mathrm{C}$. The reaction was stirred for 3 hours, and then neutralized with an aqueous solution of $30 \% \mathrm{NaOH}$ (approximately $12 \mathrm{~mL}$ ) in an ice bath. The reaction mixture was extracted with $\mathrm{CH}_{2} \mathrm{Cl}_{2}$ and the organic phases were combined, dried over $\mathrm{MgSO}_{4}$, and concentrated. The products were immediately analysed.

\section{Acknowledgments}

The authors thank FINEP-Financeira de Estudos e Projetos for financial support, FAPESP-Fundação de Amparo à Pesquisa do Estado de São Paulo for a scholarship to Melina A. Machado, Dr. Ronaldo Aloise Pilli for reagents and lab facilities and Prof. Dr. Carol H. Collins for her kind attention in revising this manuscript.

\section{References}

1. Harris, M. I. N. C.; Braga, A. C. H.; J. Braz. Chem. Soc. 2004, 15, 971; Harris, M. I. N. C.; Ph.D. Thesis, Universidade Estadual de Campinas, Brazil, 1993; Braga, A. C. H.; Harris, M. I. N. C.; Br PI 9.502.467-0, 1995. (CA 128:243740).

2. For a comprehensive review of uses of borohydrides in carboxylic acid media see: Gribble, G. W.; Nutaitis, C. F.; Org. Prep. Proced. Int. 1985, 17, 317; Gribble, G. W.; Chem. Soc. Rev. 1998, 27, 395.

3. For a better understanding of this reactivity, theoretical studies are in progress.

4. When sodium borohydride is added to excess acetic acid, hydrogen is liberated rapidly. The species in this reaction has been suggested to be sodium triacetoxyborohydride.

5. Marchini, P.; Liso, G.; Reho, A.; J. Org. Chem. 1975, 40, 3453.

6. Evans, D. A.; Chapman, K. T.; Carreira, E. M.; J. Am. Chem. Soc. 1988, 110, 3560.

7. Palmieri, G.; Cimarelli, C.; Arkivoc 2006, 104.

Received: March 28, 2006

Published on the web: August 30, 2006

FAPESP helped in meeting the publication costs of this article. 